\title{
Evaluating the impact of a web-based resource on student learning ${ }^{1}$
}

\author{
Matthew Olczak ${ }^{2}$ \\ 3rd Draft \\ January 2013
}

\begin{abstract}
This paper reports on an experiment of using a publisher provided web-based resource to make available a series of optional practice quizzes and other supplementary material to all students taking a first year introductory microeconomics module. The empirical analysis evaluates the impact these supplementary resources had on student learning. First, we investigate which students decided to make use of the resources. Then, we analyze the impact this decision has on their subsequent performance in the examination at the end of the module. The results show that, even after taking into account the possibility of self-selection bias, using the web-based resource had a significant positive effect on student learning.
\end{abstract}

JEL Classification codes: A20, A22

Keywords: Web-based resources, computer assisted assessment, self-selection bias

\footnotetext{
${ }^{1}$ I would like to thank Catherine Foster and Chris Jones for help collecting the data and Nigel Driffield, Helen Higson, David Saal, Anne Wheeler, an anonymous referee and participants at the 2011 DEE Conference and the 2012 ABS/HEA L\&T Conference for their helpful comments on an earlier draft.

${ }^{2}$ Economics and Strategy Group, Aston Business School, Aston University, Birmingham, B4 7ET, UK. m.olczak@aston.ac.uk, Tel: +441212043107.
} 


\section{Introduction}

In the mid 1990s undergraduate economics teaching in the US was, according to the survey results of Becker and Watts (1996), dominated by 'chalk and talk' teaching methods with little innovation and very limited use of technology. A follow-up survey in 2000 (Becker and Watts, 2001) suggested that little had changed, despite more attention being dedicated to teaching. However, recent evidence suggests that the use of technology is now becoming a more common means of enhancing the student learning experience. When Becker and Watts (2008) repeated their survey in 2005 they found more evidence of innovation and use of technology. Likewise, survey evidence from economics lecturers in the UK shows a significant recent increase in the adoption of technology ${ }^{3}$. However, despite this increased adoption of technology, there remains limited and inconsistent evidence on whether this has a positive impact on student learning (see section 2). This paper contributes to the available evidence by analysing which students decide to make use of a technological innovation and how this then impacted on their learning.

The paper evaluates the impact of increased use of technology in a first year introductory microeconomics module taken by over 400 business school students. Motivating and engaging students on this module is particularly difficult because class sizes are large and whilst some students are experiencing economics for the first time, others have considerably more experience of the subject. However, engaging these students is arguably of particular importance since a number of threshold concepts are introduced and, according to Shanahan et al. (2006, p.30), act as 'a portal which, when crossed by the learner, grants access to a previously inaccessible way of thinking.' Furthermore, Rhodd et al. (2009) provide evidence that performance on principles of economics courses has an important effect on overall degree

\footnotetext{
${ }^{3}$ See: http://www.economicsnetwork.ac.uk/projects/lec survey2005.pdf, pp. 8-10 (accessed 11/01/13).
} 
achievement and result, due to common methods of understanding, in spillovers on related noneconomics courses.

In an attempt to increase student engagement we experimented with introducing a webbased resource (WBR) into our teaching of this course. Such online resources are a rapidly developing part of the economics textbook market (Lopus and Paringer, 2011). The MyEconLab resource ${ }^{4}$ we introduced was provided by the publisher alongside the course textbook (Sloman and Wride, 2009). Throughout the course we used the WBR to make available to all students a series of optional practice and revision quizzes. Whilst these quizzes did not count towards the module assessment, we tried to provide clear incentives to use the resource. This was done by guaranteeing that a number of the multiple choice practice questions would be replicated in the exam at the end of the module which, for administrative reasons, was the only form of assessment.

The WBR was the only way in which students could access this practice material. Whilst this is clearly not the only means to provide students with such practice material, there are a number of benefits from providing them in this way ${ }^{5}$. First, the WBR provides a wide range of practice questions (in section 6 we discuss how this is especially useful if the WBR is also used for assessment) and also includes many other supporting materials to complement the textbook material. Whilst there are a large number of multiple-choice type questions, other question formats are also provided, including questions which provide practice in drawing and interpreting graphs. Second, the WBR enables students to receive rapid and detailed feedback

\footnotetext{
${ }^{4}$ http://myeconlab.mathxl.com/login econ.htm (accessed 11/01/13). For an overview of how MyEconLab can be used to support teaching and the range of resources provided see: http://www.youtube.com/watch?v=3ATftPOYDRY\&context=C347e269ADOEgsToPDskIn37 Kl1m5f8oUpt164DY (accessed 11/01/13).

${ }^{5}$ See also for example Chalmers and McAusland (2002) and Pollock et al. (2000) for a discussion of these and other potential benefits of computer assisted learning and assessment, including: making sure that students cover all of the course topics, allowing students to work at their own pace, improved retention rates and time savings on setting and marking assignments. They also suggest that students are generally in favour of this form of assessment.
} 
and in addition an individual study plan is generated for each student based on the areas which they have found difficult. Finally, instructors are able to easily identify and respond to areas students are finding difficult to understand. Overall, consistent with learning theory (see Simkins, 1999, pp. 278-280), we hoped that introducing the WBR would enable the students to become more active in the learning process with increased opportunities to check their understanding of the lecture material and lead to improved performance in the module. On the other hand since students have a variety of learning styles (see for example Biggs and Tang, 2007, pp. 8-30) the WBR may, therefore, not appeal to all students and our analysis will also identify such students.

There were two ways in which students could obtain access to the WBR. First, an access code was provided with a purchase of the course textbook. However, we could not require all students to purchase the textbook (which was nevertheless also available from the library). Therefore, second, in order to provide access to the resource to students who were not willing or able to purchase the textbook, the business school purchased additional access codes. These were made available to all of the students at the start of the module and for a limited period towards the end of the module ${ }^{6}$. In total $57 \%$ of students registered to use the WBR, the majority of whom (84\%) gained access by purchasing the textbook ${ }^{7}$.

The aim of this paper is to evaluate the impact the decision to use the resource had on student learning. The way in which we introduced the WBR provides a rare opportunity to analyse student decisions when they are given considerable freedom over their individual learning. The analysis will be broken down into two stages. First, we will assess which students used the WBR. Were these the students we would expect to get the most benefit e.g. those

\footnotetext{
${ }^{6}$ These codes provided access to an identical resource except for no access to the e-book version of the textbook.

${ }^{7}$ It is also possible that other students purchased the textbook and registered for the general WBR but not for the specific content we provided. These students would not be identified in our dataset. However, we believe the incentive mechanism described above makes this relatively unlikely. Likewise, it also possible that a few students shared a single registration.
} 
taking economics for the first-time? Are there certain types of students that are less likely to engage with these study materials? Second, it will then be possible to assess the impact using the resource had on student learning as measured by their performance in the final exam. Crucially, this econometric analysis of student performance will take into account the first stage decision whether or not to use the resource. This is important because otherwise a finding that using the WBR improves student learning may in fact be simply a result of the better performing students being more likely to sign up and use the resource. As outlined in the next section, previous studies have not taken this possible self-selection bias into account.

After summarising the related literature in section 2, the remainder of the paper proceeds as follows: section 3 describes our dataset and then section 4 outlines the empirical methodology. Section 5 describes the results of the empirical analysis and finally section 6 concludes.

\section{Related literature}

There is an extensive literature that examines the impact homework has on academic performance at school or university, with the general consensus being that it has a beneficial effect (see for example Palocsay and Stevens, 2008, pp. 215-7, for a detailed review of this literature). A more recent literature considers the impact technological innovation can have in university teaching and, particularly relevant for this paper, examines the use of technology to provide supplementary material including both assessed and optional quizzes. Typically, such studies compare the impact of a change in teaching method on student performance, using repetitions of the same course without the change as a control group.

Some studies compare technological solutions with other more traditional methods of teaching. In one of the first studies providing econometric evidence, Agarwal and Day (1998) examined the impact of using the internet in economics classes for: disseminating information, providing a discussion forum and project research. They found that using the internet in this way 
increased student performance. In addition, instructor evaluations improved and there was also some evidence that student attitudes to the subject improved. Their results were inconclusive as to whether the internet was more beneficial for the more or less able students. More recently, Dufresne et al. (2002) found weak evidence that web-based homework improves performance on a physics course compared to traditional paper-and-pencil based homework. On the other hand, Palocsay and Stevens (2008) find little difference between publisher and lecturer designed WBRs for providing supplementary material to undergraduate students on a business statistics course. Other studies compare performance when technology is used to provide supplementary materials rather than simply as an alternative method of provision. For example, Harter and Harter (2004) find that providing optional online quizzes when teaching economics to mainly pharmacy students does not improve student performance. Galizzi (2010) reports similar findings from economics courses where completion of the quizzes counted towards a student's assessment. Furthermore, in this case students appeared to do no better on questions that were repeated from the quizzes in comparison with performance on other questions in the exam. In contrast, Kibble (2007) found that optional quizzes do have a positive impact on performance in a physiology course. In addition, rewarding students with credit for taking the quizzes resulted in a significant increase in participation. Hadsell (2009) also finds a positive effect of optional quizzes, especially when students are given longer to complete the quizzes, despite this reducing the available feedback. Likewise, Lass et al. (2007) find evidence that assessed quizzes improve performance in a statistics module.

In such studies, in order isolate the impact changing the teaching method has on student performance, it is crucial that this is the only thing that changes across repetitions of the same module. For example, the assessment must be kept as similar as possible. In addition, whilst student characteristic data can be used as controls, there may also be unobservable differences across intakes. A crucial difference in our approach is that we conduct a cross-sectional analysis of student performance for a single intake on the module where the WBR was available 
to all students. Like studies such as Harter and Harter (2004), the online quizzes and other supplementary material are optional. However, in previous such studies there has typically been no analysis of the student decision whether or not to attempt the quizzes ${ }^{8}$. In contrast, we first analyse the student decision whether or not to make use of the supplementary material. Second, we then analyse the impact this decision has on subsequent performance using the first stage analysis to control for the possibility of self-selection bias. This is done using a treatment-effects methodology described in section 4. Whilst this methodology has been used extensively in a wide range of economic applications, it has been far less commonly used in learning and teaching research. To the best of our knowledge, when analysing the impact WBRs have on performance none of the previous studies have explicitly controlled for the possibility of self-selection bias. A related paper is Driffield et al. (2011) who use the same empirical methodology as we will adopt here, but their focus is on the impact of the student decision whether or not to undertake a work-experience placement year.

\section{Data}

Our sample covers the 446 students who completed the final exam for this module. As explained earlier, students could gain access to the WBR either by purchasing the course textbook or using the free codes purchased by the business school. Table 1 shows that in total $254(57 \%)$ of the students made use of the resource of which $84 \%$ gained access by purchasing the book. The table then summarises the total amount of time that students spent using the WBR.

[Table 1 here]

\footnotetext{
${ }^{8}$ Two exceptions are Catley (2008) and Hadsell (2009) however here self self-selection bias is not explicitly controlled for.
} 
The average student who made use of the resource did so for a total of just over two hours across the term ${ }^{9}$. Interestingly, the table also shows that on average there was no difference in usage according to the method by which the student gained access.

This module was assessed by a two hour examination taken at the end of the module. The exam had two sections with equal weighting. Section A contained 50 multiple choice questions of which 10 exactly replicated questions from the large number of practice questions provided via the WBR quizzes. Section B then contained 6 short answer questions of which the students were required to answer 4. Appendix 1 shows that across all students the average overall exam mark was $52 \%$ and $29 / 50$ for the multiple choice (MC) section. It should be noted that under the UK marking system a mark between 50 and $59 \%$ corresponds to a $2: 2$ which is the 3rd highest degree classification available, with a mark of $70 \%$ or above required for the highest classification. We can then see how exam performance differs depending upon whether the student made use of the WBR. Figure 1 shows that students that made use of the WBR on average performed better on both parts of the exam (see Appendix 1 for more detail).

[Figure 1 here]

Regardless of access method, t-tests confirm that the students who registered for the WBR performed significantly better both on the multiple choice section and the overall exam $(p<$ 0.01). However, we have not yet taken into account which students decided to use the WBR or in other words haven't accounted for the possible self-selection bias. It is therefore too early to conclude that this demonstrates considerable increased student learning through using the WBR.

\footnotetext{
9 This only includes time spent on the assigned quizzes not the individual study plan and other supplementary material.
} 
Table 2 provides descriptive statistics for the student characteristic data from the university student records database that will be used in the econometric analysis. For each of the 446 students we first have information on their age at the start of the course, their gender and whether they are a home, EU or overseas student. The majority of students are male (60\%) and have recently left school/college. In addition, there are a relatively large proportion of overseas students (33\%). In the UK system students are typically awarded palaces at university based on A-level and AS-level (half an A-level) qualifications obtained in three or more subjects. Therefore, the UCAS entry score variable measures the AS and A-level qualifications of the student prior to entering university ${ }^{10}$. This will be a useful control variable to measure the academic ability of a student at the start of their degree programme. However, not all students meet the university entry requirements by A-level qualifications, with alternatives including Foundation Programmes, the International Baccalaureate (IB) and other overseas qualifications. Therefore, unfortunately this variable is only available for 250 of the 446 students. The empirical analysis in section 5 will take this into account. In addition, based on the UCAS and IB information Economics and Maths are dummy variables indicating whether or not the student has taken these subjects. Then, for the students who have taken economics to AS or A-level the Econ UCAS score variable measures the student's score for the highest level obtained. Finally, Table 2 also reports on three additional categories of variables: the degree programme that the student is enrolled on, the occupation category of the students' parents and the type of establishment in which the student gained their pre-university education. We can distinguish between pre-university education in fee charging independent schools, state-funded selective grammar schools, comprehensive schools which are neither selective nor fee charging and higher education colleges. Unfortunately, for both pre-university education and parental

\footnotetext{
${ }^{10}$ A-level grades of: A, B, C, D and E are given a tariff score of: 120, 100, 80,60 and 40 respectively and an AS-level qualification counts for half of this score.
} 
occupation the data is again not available for a relatively large number of the students and in the empirical analysis these will be treated as the base category.

[Table 2 here]

\section{Methodology}

We are interested in explaining student's examination performance $\left(y_{i}\right)$. This will be modelled as

$$
y_{i}=x_{i}^{\prime} \beta+\delta z_{i}+\varepsilon_{i}
$$

where $x_{i}$ is a vector of characteristics of student $i$ (see Table 2), $z_{i}$ is a binary variable capturing whether or not student $i$ decided to register for the WBR and $\varepsilon_{i}$ is an error term. The primary focus of this research is on the impact of the WBR on exam performance captured by the parameter $\delta$. Equation 1 can be estimated by Ordinary Least Squares (OLS), however, this may under (or over) estimate the treatment effect. This will be the case if the typical student who chooses to use the WBR would have had a relatively high (or low) exam performance regardless of whether they decided to use the resource (see Greene, 2003, p.788 for a formal demonstration of this self-selection bias) ${ }^{11}$.

A solution to this problem is to estimate a treatment-effects model using a two-step procedure $^{12}$. First, a model of each student's decision whether or not to use the WBR is estimated. Assume the likelihood student $i$ uses the resource $\left(z_{i}^{*}\right)$ is given by

$$
z_{i}^{*}=w_{i}^{\prime} \gamma+u_{i}
$$

\footnotetext{
${ }^{11}$ This problem is similar to that of sample-selection bias. However here, subsequent exam performance is observed for all students, not just those using the WBR. Heckman (1976) proposed a solution (described below) which can be used both for correcting for sample-selection bias (see Wooldridge, 2006, pp. 615-23) and for self-selection bias.

${ }^{12}$ It is also possible (see footnote 16, p. 12) to estimate the model using full maximum likelihood (see Maddala, 1983, pp. 120-2.). This uses information on the joint distribution of $y$ and $z$.
} 
where $w_{i}$ is a vector of characteristics of student $i$ (and can include variables in $x_{i}$ above) and $u_{i}$ is an error term. However, we do not observe the likelihood that student $i$ adopts the resource, instead we observe the binary decision $\left(z_{i}\right)$ of each student. Each student adopts the resource $\left(z_{i}=1\right)$ if the likelihood is sufficiently high. Therefore we can write the observed decision of student $i$ as

$$
z_{i}=\left\{\begin{array}{l}
1 \text { if } z_{i}^{*}>0 \\
0 \text { otherwise }
\end{array}\right.
$$

If we assume the error term $\left(u_{i}\right)$ is normally distributed then the probability that an individual adopts the WBR can be estimated using a probit model.

Second, equation 1 can then be estimated using the results from the probit model to correct for the self-selection bias $^{13}$. This estimation will also report on the correlation between the error terms $\varepsilon_{i}$ and $u_{i}$. This $\rho$ parameter captures the extent to which an OLS regression over/under estimates the treatment effect $(\delta)$ due to the self-selection bias described above.

Maddala (1983, p.120) explains that this model can be estimated even if $w_{i}$ includes all the variables in $x_{i-}{ }^{14}$. However, it is preferable to estimate the model with at least one variable included as an instrument for $z_{i}^{*}$ and therefore not also included in $x_{i}$. In other words, ideally at least one variable should be included which affects the likelihood that students adopt the WBR but does not affect their performance (we discuss this issue further in the next section).

\section{Results}

As discussed earlier, a student's UCAS entry score is an important control variable but this data is only available for 250 of the students. Our initial analysis will, therefore, focus on this (UCAS) subsample which is largely made up of home students. In this subsample 159 (64\%) of the

\footnotetext{
${ }^{13}$ See Greene (2003, p.788) for a formal description of the correction procedure.

${ }^{14}$ The model is still identified because of the non-linearity of the probit regression.
} 
students registered for the WBR of which 136 paid to gain access. In Appendix 2 the descriptive statistics are replicated for the key characteristics of the students in this subsample.

The first step in our empirical analysis is to estimate a probit model of the probability that a student registers to use the WBR. Experimentation shows that the available student characteristic data are much better able to explain the probability that a student pays to use the WBR rather than the probability that they register for the resource by either method. We therefore initially focus on the student decision whether or not to pay to access the resource. Table 3 shows the variables that significantly affect this decision.

[Table 3 here]

The reported coefficients are marginal effects which show the change in the probability that a student pays to use the resource compared to the reference group, holding all other variables at their mean values. Therefore, the results show that students that we know went to comprehensive or grammar schools are respectively 18 and $12 \%$ more likely to pay to use the WBR. In addition, a $1 \%$ increase in age relative to the mean increases the probability that a student pays to use the WBR by $12 \%$. All other explanatory variables had an insignificant effect and have therefore been omitted from the model. In particular, overall previous academic performance and qualifications in economics and/or maths do not significantly effect this decision. This last finding is somewhat surprising since we might in particular expect students with previous experience of economics to perceive that they have less need for practice questions. Our results suggest that this effect may be counteracted by such students being more interested in the subject and/or more aware of the benefits of repeated practice.

Having examined the determinants of the probability that the student pays to use the WBR, in stage 2 we examine the impact this decision has on subsequent performance in the examination. Initially, we will focus on students overall performance in the exam. The first set of 
results in Table 4 are for an OLS regression explaining overall examination marks. Here, the binary variable capturing the student decision to pay to use the WBR is simply included as an explanatory variable. The coefficient on this variable is positive and highly significant. This suggests, like the earlier comparison of average marks, that the WBR improves student performance. However, this OLS regression does not control for the self-selection problem discussed earlier.

Therefore, in order to allow for the possibility of self-selection bias, we now use the twostep approach described in section 4. Table 4(2) reports the results for stage 2 of a treatmenteffects regression, with the stage 1 decision as estimated in Table 3. As explained earlier, ideally, at least one explanatory variable should be included in stage 1 that does not affect student performance and is therefore omitted in stage 2. Table 3 showed that age and previous education establishment significantly affect the probability that a student pays to access the WBR. This may for example reflect differences in teaching approaches used across establishments and different attitudes to learning. However, having controlled for student ability, we would not expect these variables to directly affect exam performance ${ }^{15}$. These variables are therefore omitted from stage 2 and used as instruments for the stage 1 decision.

Crucially, the results of the treatment-effects regression show that the positive coefficient on the WBR variable has increased in magnitude and is highly significant ${ }^{16}$. Furthermore, the $\rho$ parameter is negative, this means that the OLS regression underestimates the effect paying to use the WBR has on exam performance.

\section{[Table 4 here]}

\footnotetext{
${ }^{15}$ It is also important to note that there is no significant correlation between a student going to a comprehensive school and their UCAS entry score.

${ }^{16}$ This coefficient remains significant if the Comprehensive variable is the only variable not included in the stage 2 regression. Furthermore, if the model is estimated using maximum likelihood methods (see footnote 12, p.9) it also remains significant if all three variables are also included in stage 2.
} 
In addition, the other control variables included show that previous academic performance and other student characteristics are also important determinants of student performance. As expected, overall UCAS score has a positive and highly significant effect, as does a maths qualification ${ }^{17}$. Interestingly, it is not simply an AS or A-level in Economics that matters but the level of qualification obtained ${ }^{18}$. In addition, male students perform significantly better $^{19}$. Finally, the positive coefficient on overseas students needs to be interpreted with caution since students which have not taken AS or A-level qualifications are excluded from this sample, a large proportion of which are overseas students.

Unreported results show that the previously omitted instrumental variables are insignificant if included in stage $2^{20}$. In addition, for comparison, the final column of Table 4 replicates the OLS regression with these explanatory variables omitted.

Our key result is therefore that, at least for this subsample of students, paying to use the WBR with a purchase of the textbook has a positive and highly significant impact on student learning. More precisely, using the results from the treatment-effects regression we can calculate that the expected exam score is on average 3.6 marks higher for students that pay to use the WBR. This is similar in magnitude to the estimated effect of using the WBR in the OLS regressions.

\footnotetext{
${ }^{17}$ In other unreported results a Maths UCAS score variable is positive but only significant if it is included instead of the Maths variable. This suggests that, in contrast to economics, having studied maths to this level is important rather than the level of qualification obtained.

${ }^{18}$ This positive impact of a background in maths and economics is consistent with the findings of Andrews and Jones (2011).

${ }^{19}$ Walstad and Robson (1997) suggest such gender differences are common and discuss possible explanations.

${ }^{20}$ The significance of the Comprehensive variable in the first OLS regression in Table 5 arises because we have not accounted for the self-selection decision in stage 1 . In other words, students that attend comprehensive schools do not perform better per se, but because they are more likely to pay to use the WBR.
} 


\section{Exam performance by section}

So far we have examined overall student performance in the final examination. Table 5 repeats the earlier treatment-effects regression but now separately for the student marks on the multiple choice and short answer sections of the exam. This will provide evidence for whether the WBR only provides help in answering multiple choice type questions or whether it also facilitates a deeper understanding of threshold economic concepts. Table 5 shows that paying to access the WBR has a positive and significant effect on performance on both sections of the exam. Furthermore, the coefficient on WBR is larger and more significant for section B of the exam. Therefore, somewhat surprisingly, the benefits a student gains from using the WBR resource appear to be even more apparent for the short answer type questions. This interesting finding will be discussed in more detail in the concluding section.

[Table 5 here]

The results also show that the level of previous knowledge in economics is a much more significant determinant of performance on the multiple choice section.

Registration for the WBR using the free access codes

In the previous two subsections we have shown that a student's decision to pay to use the WBR had a significant effect on their performance at the end of the module. Next, we will examine whether this result continues to hold for all students who registered to use the resource. Therefore, in the stage 1 probit regression shown in Table 6, the dependent variable is a binary variable indicating the decision to register for the WBR by either available means. Here, whilst the results are quantitatively similar, the coefficients are far less significant; as explained earlier 
the student characteristic data is less good at explaining the decision to access the WBR via either means.

[Table 6 here]

Table 7 then reports the results for stage 2. Although less significant the coefficient on the WBR variable remains positive and is significant at the $5 \%$ level.

[Table 7 here]

This therefore confirms that our key finding holds, regardless of the method by which students choose to access the WBR. Students that use the free codes do not buy the textbook so these results provide some additional support for interpreting our key finding as showing a positive impact from using the WBR beyond the benefits from buying the textbook. In addition, the coefficients on the other explanatory variables in Table 7 are similar to the earlier results.

\section{Full sample}

So far all the analysis has been conducted on the subsample of students for which UCAS data was available. In this section we widen our analysis to the complete sample of 446 students. Tables 8 and 9 report the results for each stage of the analysis, now again focusing on the decision of whether to pay to access the resource.

\section{[Table 8 here]}

Table 8 shows that again, a grammar or comprehensive school education makes a student more likely to pay to access the WBR, however, the age variable is no longer significant. 
Interestingly, Table 8 also shows that within the full sample, overseas students are much less likely to pay to access the resource. Explanations for this finding will be discussed in the next section.

[Table 9 here]

Because we no longer include a control variable for student academic ability on joining university caution needs to be taken in interpreting these results. However, Table 9 suggests that our key finding also holds for the full sample; students that pay to use the WBR resource perform significantly better at the end of the module.

\section{Conclusion}

Our experiment with introducing supplementary optional material via a WBR provided an ideal opportunity to analyse student behaviour when they are given considerable freedom over their individual learning. The findings of our empirical analysis clearly show that making use of the WBR had a positive impact on student learning. The module studied here was ideal for examining the impact of supplementary WBRs because of the theoretical nature of the material, the similarities between the practice and assessment questions and the apparent benefits of repetition for increasing student understanding of threshold concepts. However, our findings should also apply in many other economics and business modules. In addition, whilst more evidence is clearly needed, they may also apply across a much wider range of disciplines. The WBR had a positive impact despite students spending a relatively short amount of time taking the assigned optional quizzes (see Table 1). However, our results may also in part be driven by the other supplementary resources provided by the WBR and the benefits students obtained from purchasing and making use of the textbook itself. Our results also show that use of the WBR impacted positively not just on student performance in the multiple choice section of the 
exam but also on the short answer questions. This finding supports the suggestion of Buckles and Siegfried (2006) that multiple choice assessments can potentially test for higher levels of understanding than is typically realised. However, Buckles and Siegfried are skeptical that many textbook question banks achieve this. Whilst additional research is clearly needed, our results suggest that, at least for the specific content of our module, this skepticism may not be merited. In addition, our results suggest that some groups of students, in particular overseas students, are less willing/able to pay to use the WBR and furthermore this decision harms their subsequent performance. For overseas students this may, for example, be because they adopt different learning styles or are less willing/able to pay for the resource given the higher university fees they are already paying. If the latter is a significant factor then in the future this may also have implications for home students' given the forthcoming significant increase in the fee ceiling. This may affect willingness to pay for supplementary materials despite the fees not being paid up-front. This clearly merits further investigation.

The overall success of our experiment suggests that further integration of the WBR in the module and encouragement to make use of it would be beneficial. One possibility is to ensure that all students are registered for the WBR and use the online quizzes for formal continuous assessment. Our results suggest that providing access to all students would be a worthwhile investment. WBRs provided by publishers are well suited to be used for assessment especially when there are a large number of students, as they provide a large question bank and allow questions to be algorithmically generated and randomized across students. The adoption of the WBR for formal assessment raises further interesting research questions. It would, for example, be interesting to investigate the behaviour of students following an assessed quiz and look at whether the students performing less well seek additional practice material or become discouraged. 
Appendix 1

Exam performance by WBR usage

\begin{tabular}{|c|ccccc|}
\hline Sample & N & Mean & Std Dev & Min & Max \\
\hline All & & & & & \\
Exam (\%) & 446 & 52 & 16 & 16 & 87 \\
MC (/50) & 446 & 29 & 7 & 12 & 47 \\
\hline WBR & & & & & \\
Exam (\%) & 254 & 57 & 15 & 20 & 87 \\
MC (I50) & 254 & 31 & 7 & 12 & 47 \\
\hline Book & & & & & \\
Exam (\%) & 213 & 57 & 14 & 20 & 87 \\
MC (I50) & 213 & 31 & 7 & 12 & 47 \\
\hline Free code & & & & & \\
Exam (\%) & 41 & 55 & 16 & 20 & 80 \\
MC (I50) & 41 & 31 & 8 & 16 & 45 \\
\hline None & & & & & \\
Exam (\%) & 192 & 47 & 16 & 16 & 82 \\
MC (I50) & 192 & 27 & 7 & 14 & 47 \\
\hline
\end{tabular}

\section{Appendix 2}

Descriptive statistics for key student characteristic variables (UCAS sample)

\begin{tabular}{|c|ccccc|}
\hline Variable & $\mathbf{N}$ & Mean & Std Dev & Min & Max \\
\hline Exam & 250 & 57 & 15 & 18 & 87 \\
MC & 250 & 31 & 7 & 12 & 47 \\
\hline Age (years) & 250 & 19.5 & 0.8 & 18.3 & 26.9 \\
Male & 250 & 0.60 & 0.49 & 0 & 1 \\
Overseas & 250 & 0.15 & 0.36 & 0 & 1 \\
European & 250 & 0.04 & 0.06 & 0 & 1 \\
\hline UCAS entry score & 250 & 361 & 112 & 20 & 610 \\
Economics & 250 & 0.38 & 0.49 & 0 & 1 \\
Econ UCAS score & 95 & 94 & 27 & 20 & 120
\end{tabular}




\begin{tabular}{|c|ccccc|} 
Maths & 250 & 0.54 & 0.50 & 0 & 1 \\
\hline Previous education & & & & & 1 \\
Comprehensive & 250 & 0.34 & 0.47 & 0 & 1 \\
Grammar & 250 & 0.08 & 0.27 & 0 & 1 \\
Independent & 250 & 0.12 & 0.33 & 0 & 1 \\
College & 250 & 0.23 & 0.42 & 0 & 1 \\
Other/N/A & 250 & 0.23 & 0.42 & 0 & \\
\hline
\end{tabular}




\section{References}

Agarwal, R. and A. E. Day (1998). The impact of the internet on economic education. Journal of Economic Education, 29, 99-110.

Andrews, J. and C. Jones (2011). Does a background in economics and maths matter? Working paper.

Becker, W. E. and M. Watts (1996). Chalk and talk: a national survey on teaching undergraduate economics. The American Economic Review, 86 (2), 448-53.

Becker, W. E. and M. Watts (2001). Teaching economics at the start of the 21st century: still chalk-and-talk. The American Economic Review, 91 (2), 446-51.

Becker, W. E. and M. Watts (2008). A little more than chalk and talk: results from a third national survey on teaching methods in undergraduate economics courses. Journal of Economic Education, 39 (3), 273-86.

Biggs, J. and C. Tang (2007). Teaching for Quality Learning at University (3rd ed.). Maidenhead: Open University Press, McGraw Hill Education.

Buckles, S. and J. J. Siegfried (2006). Using multiple choice questions to evaluate in-depth learning of economics. Journal of Economic Education, 37 (1), 48-57.

Catley, P. (2008). Online formative assessment: does it work? Presentation at the UKCLE seminar on e-assessment, Bristol, January. http://www.ukcle.ac.uk/resources/assessment-and-feedback/online-formativeassessment/ (accessed 11/01/13)

Chalmers, D. C. and W. D. M. McAusland (2002). Computer-assisted assessment. In The Handbook for Economics Lecturers. http://www.economicsnetwork.ac.uk/handbook/printable/caa v5.pdf (accessed 11/01/13) 
Driffield, N. L., C. S. Foster, and H. E. Higson (2011). Does undertaking an integrated work placement as part of your degree get you better marks, or do 'better' students do a placement? Working paper.

Dufresne, R., J. Mestre, D. M. Hart, and K. A. Rath (2002). The effect of web-based homework on test performance in large enrollment introductory physics courses. Journal of Computers in Mathematics and Science Teaching, 21 (3), 229-51.

Galizzi, M. (2010). An assessment of the impact of online quizzes and textbook resources on students' learning. International Review of Economics Education, 9 (1), 31-43.

Greene, W. H. (2003). Econometric Analysis (5th ed.). Upper Saddle River, N.J.: Prentice Hall.

Hadsell, L. (2009). The effect of quiz timing on exam performance. Journal of Education for Business, 84 (3), 135-40.

Harter, C. L. and J. F. R. Harter (2004). Teaching with technology: does access to computer technology increase student achievement? Eastern Economic Journal, 30 (4), 507-514.

Heckman, J. J. (1976). The common structure of statistical models of truncation, sample selection and limited dependent variables and a simple estimator for such models. Annals of Economic and Social Measurement, 5, 475-92.

Kibble, J. (2007). Use of unsupervised online quizzes as formative assessment in a medical physiology course: effects of incentives on student participation and performance. Advances in Physiology Education, 31, $253\{60$.

Lass, D., B. Morzuch, and R. Rogers (2007). Teaching with technology to engage students and enhance learning. University of Massachusetts Amherst, Department of Resource Economics, Working Paper 2007-1. http://courses.umass.edu/resec/workingpapers/documents/ResEcWorkingPaper20071.pdf (accessed 11/01/13) 
Lopus, J. S. and L. Paringer (2011). The principles of economics textbook. In G. H. Holt and K. McGoldrick (Eds.), International Handbook on Teaching and Learning Economics.

Maddala, G. S. (1983). Limited-dependent and qualitative variables in econometrics. Cambridge: Cambridge University Press.

Palocsay, S. W. and S. P. Stevens (2008). A study of the effectiveness of web-based homework in teaching undergraduate business statistics. Decision Sciences of Innovation Education, 6 (2), 213-32.

Pollock, M. J., C. D. Whittington, and G. F. Doughty (2000). Evaluating the costs and benefits of changing to CAA. Paper presented at the 4th CAA Conference, Loughborough University.

http://www.caaconference.com/pastConferences/2000/proceedings/pollockm.pdf (accessed 11/01/13)

Rhodd, R. G., S. M. Schrouder, and M. T. Allen (2009). Does the performance on principles of economics courses affect the overall success of undergraduate business majors? International Review of Economics Education, 8 (1), 48-63.

Shanahan, M. P., G. G Foster, and J. H. F. Meyer (2006). Operationalising a threshold concept in economics: a pilot study using multiple choice questions on opportunity costs. International Review of Economics Education, 5 (2), 29-57.

Simkins, S. P. (1999). Promoting active-student learning using the worldwide web in economics courses. Journal of Economic Education, 30 (3), 278-291.

Sloman, J. and A. Wride (2009). Economics (7th ed.). Prentice Hall, An imprint of Pearson Education.

Walstad, W. B. and D. Robson (1997). Differential item functioning and male-female differences on multiple-choice tests in economics. Journal of Economic Education, 28 (2), 155-72. 
Wooldridge, J. M. (2006). Introductory Economics: A Modern Approach ( $3^{\text {rd }}$ International Student ed.). Mason, Ohio: Thomson, South Western. 
Table 1: Student usage of the WBR (in minutes)

\begin{tabular}{|c|ccccc|}
\hline Sample & N & Mean & Std Dev & Min & Max \\
\hline WBR & 254 & 131 & 205 & 1 & 1320 \\
\hline Book & 213 & 131 & 214 & 1 & 1320 \\
Free code & 41 & 131 & 151 & 5 & 578 \\
\hline
\end{tabular}

Figure 1: Average exam marks by section depending on WBR usage

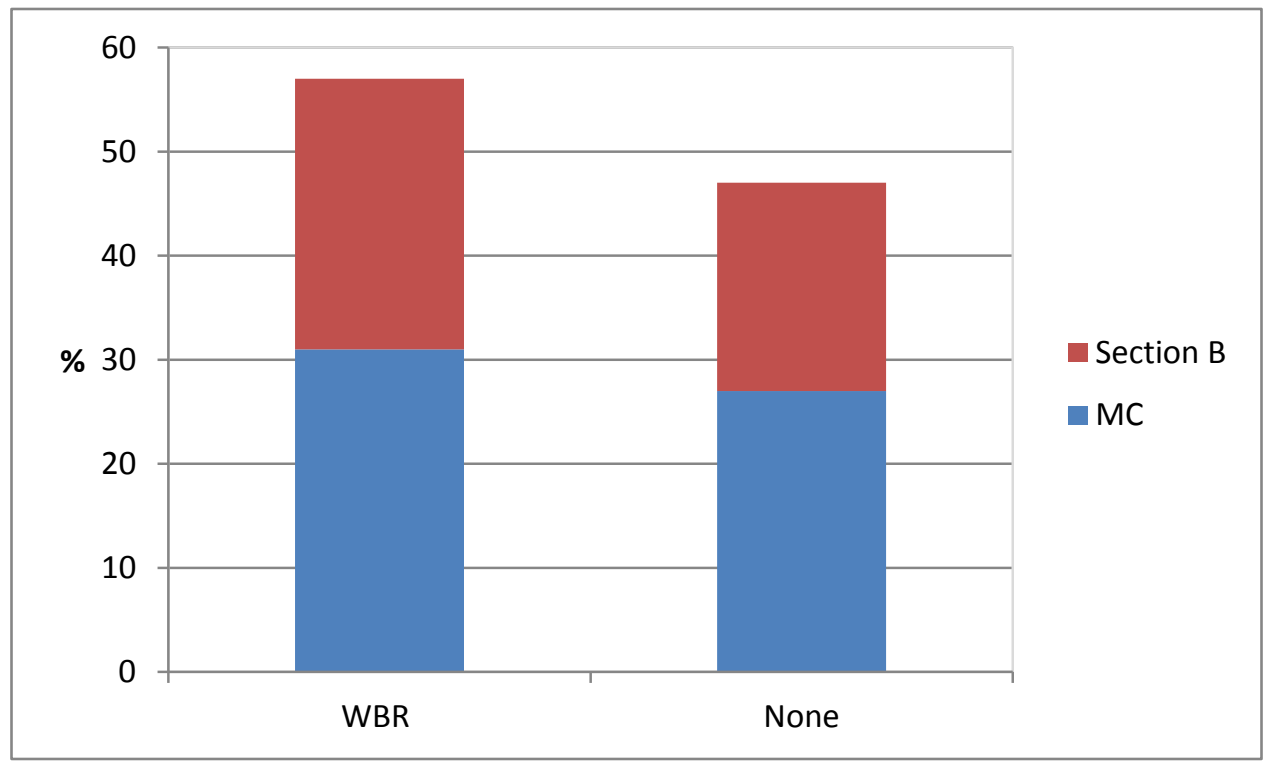

Table 2: Descriptive statistics for the student characteristic variables

\begin{tabular}{|c|ccccc|}
\hline Variable & N & Mean & Std Dev & Min & Max \\
\hline Age (years) & 446 & 20.2 & 2.09 & 18.3 & 41.1 \\
Male & 446 & 0.60 & 0.49 & 0 & 1 \\
Overseas & 446 & 0.33 & 0.47 & 0 & 1 \\
European & 446 & 0.04 & 0.20 & 0 & 1 \\
\hline UCAS entry score & 250 & 361 & 112 & 20 & 610 \\
Economics & 446 & 0.24 & 0.43 & 0 & 1 \\
Econ UCAS score & 102 & 94 & 28 & 0 & 1 \\
Maths & 446 & 0.34 & 0.47 & 0 & 1 \\
Business \& Management & 446 & 0.50 & 0.50 & 0 &
\end{tabular}




\begin{tabular}{|c|c|c|c|c|c|}
\hline $\begin{array}{c}\text { Accounting for Management } \\
\text { and Finance }\end{array}$ & 446 & 0.19 & 0.39 & 0 & 1 \\
\hline $\begin{array}{c}\text { International Business \& } \\
\text { Economics }\end{array}$ & 446 & 0.07 & 0.25 & 0 & 1 \\
\hline Mathematics with Economics & 446 & 0.07 & 0.25 & 0 & 1 \\
\hline Economics \& Management & 446 & 0.09 & 0.29 & 0 & 1 \\
\hline Management \& Strategy & 446 & 0.04 & 0.21 & 0 & 1 \\
\hline Other & 446 & 0.03 & 0.18 & 0 & 1 \\
\hline \multicolumn{6}{|l|}{ Previous education } \\
\hline Comprehensive & 446 & 0.20 & 0.40 & 0 & 1 \\
\hline Grammar & 446 & 0.04 & 0.21 & 0 & 1 \\
\hline Independent & 446 & 0.13 & 0.34 & 0 & 1 \\
\hline College & 446 & 0.17 & 0.38 & 0 & 1 \\
\hline Other/N/A & 446 & 0.45 & 0.50 & 0 & 1 \\
\hline \multicolumn{6}{|l|}{ Parent's occupation } \\
\hline $\begin{array}{c}\text { Higher managerial \& } \\
\text { professional }\end{array}$ & 446 & 0.04 & 0.19 & 0 & 1 \\
\hline Intermediate & 446 & 0.09 & 0.28 & 0 & 1 \\
\hline $\begin{array}{l}\text { Lower managerial \& } \\
\text { professional }\end{array}$ & 446 & 0.22 & 0.41 & 0 & 1 \\
\hline Lower supervisory \& technical & 446 & 0.05 & 0.22 & 0 & 1 \\
\hline Semi-routine & 446 & 0.02 & 0.14 & 0 & 1 \\
\hline $\begin{array}{l}\text { Small employers and own } \\
\text { account }\end{array}$ & 446 & 0.07 & 0.25 & 0 & 1 \\
\hline Other/N/A & 446 & 0.52 & 0.50 & 0 & 1 \\
\hline
\end{tabular}

Table 3: Probit regression - the probability a student pays to access the WBR (UCAS sample)

\begin{tabular}{|c|c|}
\hline Variable & $\begin{array}{c}\text { Marginal } \\
\text { effect }\end{array}$ \\
\hline Age & $-0.117^{\star \star}$ \\
$(0.048)$ \\
Comprehensive & $0.178^{\star \star \star}$
\end{tabular}




\begin{tabular}{|c|c|} 
Grammar & $(0.068)$ \\
& $0.205^{\star}$ \\
$(0.107)$
\end{tabular}

*** Significantly different from 0 at $1 \%$ level, ${ }^{* *}$ significantly different from 0 at $5 \%$ level and * significantly different from 0 at $10 \%$ level. Standard errors in parenthesis.

Table 4: OLS and treatment-effects regressions explaining overall exam performance (UCAS sample)

\begin{tabular}{|c|c|c|c|}
\hline & $\begin{array}{c}1 \\
\text { OLs } \\
\text { Coefficient }\end{array}$ & $\begin{array}{c}2 \\
\text { Treatment-effects } \\
\text { Coefficient }\end{array}$ & $\begin{array}{c}3 \\
\text { OLS } \\
\text { Coefficient }\end{array}$ \\
\hline WBR & $\begin{array}{l}3.745^{\star \star} \\
(1.589)\end{array}$ & $\begin{array}{c}18.978^{\star \star \star} \\
(7.019)\end{array}$ & $\begin{array}{l}4.459 * * \star \\
(1.564)\end{array}$ \\
\hline UCAS entry score & $\begin{array}{l}0.036^{\star \star *} \\
(0.007)\end{array}$ & $\begin{array}{l}0.034^{\star \star \star} \\
(0.007)\end{array}$ & $\begin{array}{l}0.036^{\star \star \star} \\
(0.007)\end{array}$ \\
\hline Economics & $\begin{array}{l}-2.122 \\
(4.750)\end{array}$ & $\begin{array}{l}-1.032 \\
(4.633)\end{array}$ & $\begin{array}{l}-1.928 \\
(4.729)\end{array}$ \\
\hline Econ UCAS score & $\begin{array}{l}0.123^{\star \star \star} \\
(0.047)\end{array}$ & $\begin{array}{l}0.119 * \star \star \\
(0.046)\end{array}$ & $\begin{array}{l}0.121^{\star *} \\
(0.047)\end{array}$ \\
\hline Maths & $\begin{array}{l}4.602^{\star \star \star} \\
(1.626)\end{array}$ & $\begin{array}{l}4.444^{\star \star \star} \\
(1.589)\end{array}$ & $\begin{array}{l}4.609 * \star \star \\
(1.628)\end{array}$ \\
\hline Male & $\begin{array}{l}5.025^{\star * \star} \\
(1.578)\end{array}$ & $\begin{array}{l}5.371^{* * *} \\
(1.527)\end{array}$ & $\begin{array}{l}5.130 * \star * \\
(1.561)\end{array}$ \\
\hline Overseas & $\begin{array}{l}4.873^{\star \star} \\
(2.390)\end{array}$ & $\begin{array}{l}4.960 * \star \\
(2.326)\end{array}$ & $\begin{array}{l}3.278 \\
(2.292)\end{array}$ \\
\hline
\end{tabular}




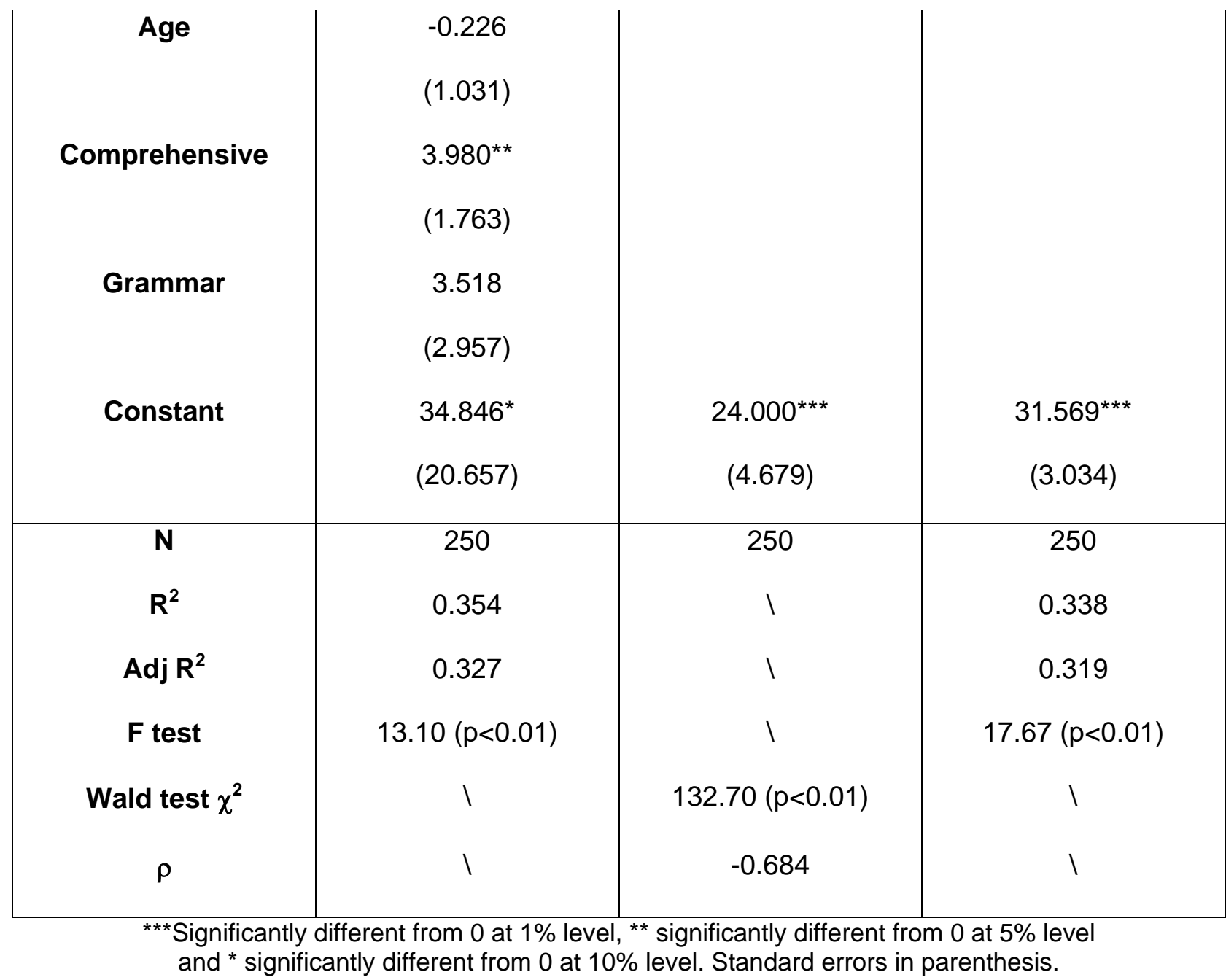


Table 5: Treatment-effects regressions explaining exam performance by section (UCAS sample)

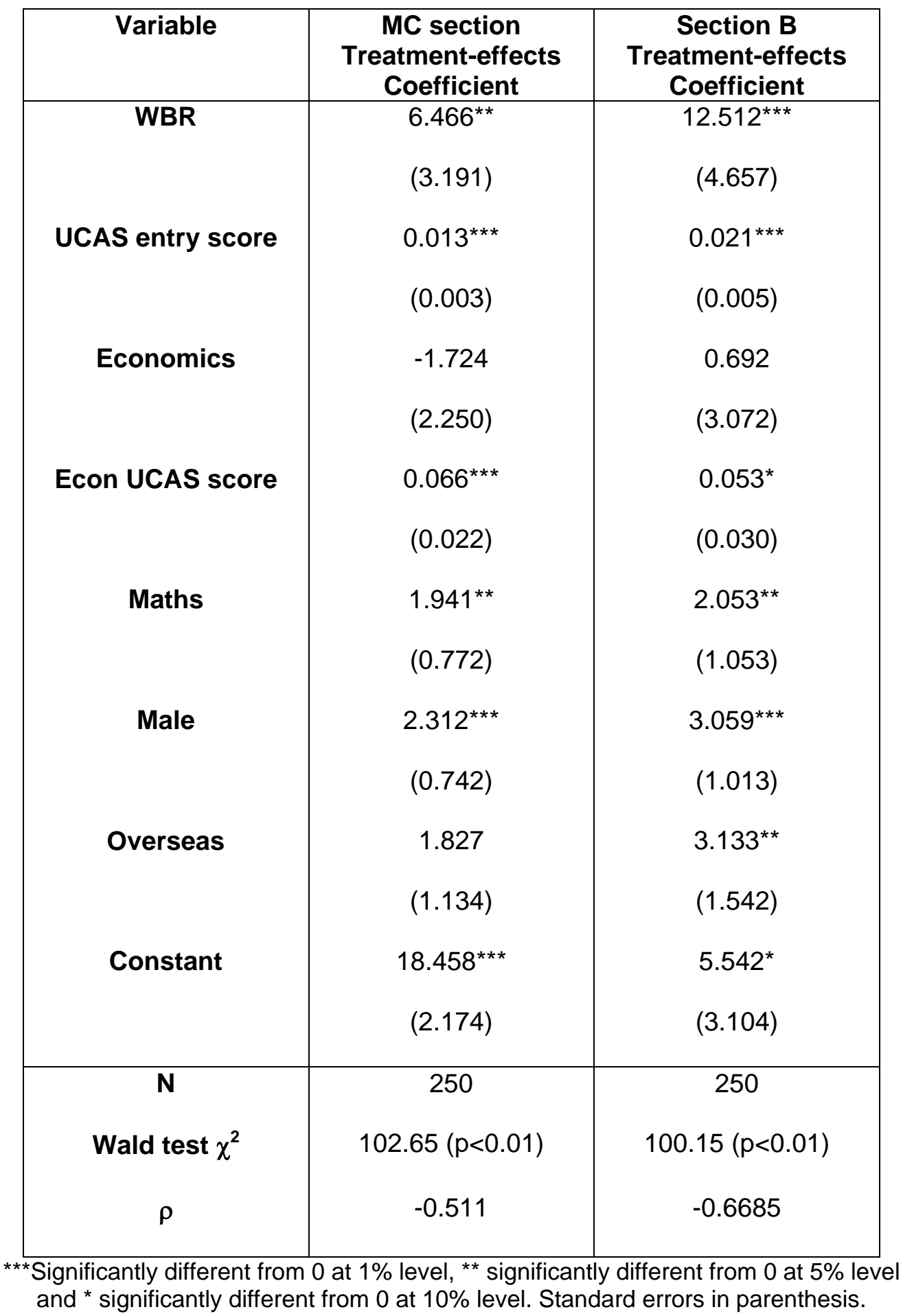


Table 6: Probit regression - the probability a student registers for the WBR (UCAS sample)

\begin{tabular}{|c|c|}
\hline Variable & Marginal effect \\
\hline Age & $-0.076^{*}$ \\
Comprehensive & $0.042)$ \\
Grammar & $(0.065)$ \\
& 0.144 \\
\hline N & $(0.101)$ \\
Log-L & 250 \\
LR test $\chi^{2}$ & -159.222 \\
Pseudo R & $9.40(p<0.05)$ \\
Correct predictions & 0.029 \\
\hline
\end{tabular}

***Significantly different from 0 at $1 \%$ level, ${ }^{* *}$ significantly different from 0 at $5 \%$ level and * significantly different from 0 at $10 \%$ level. Standard errors in parenthesis. 
Table 7: Treatment-effects regression explaining overall exam performance (UCAS sample)

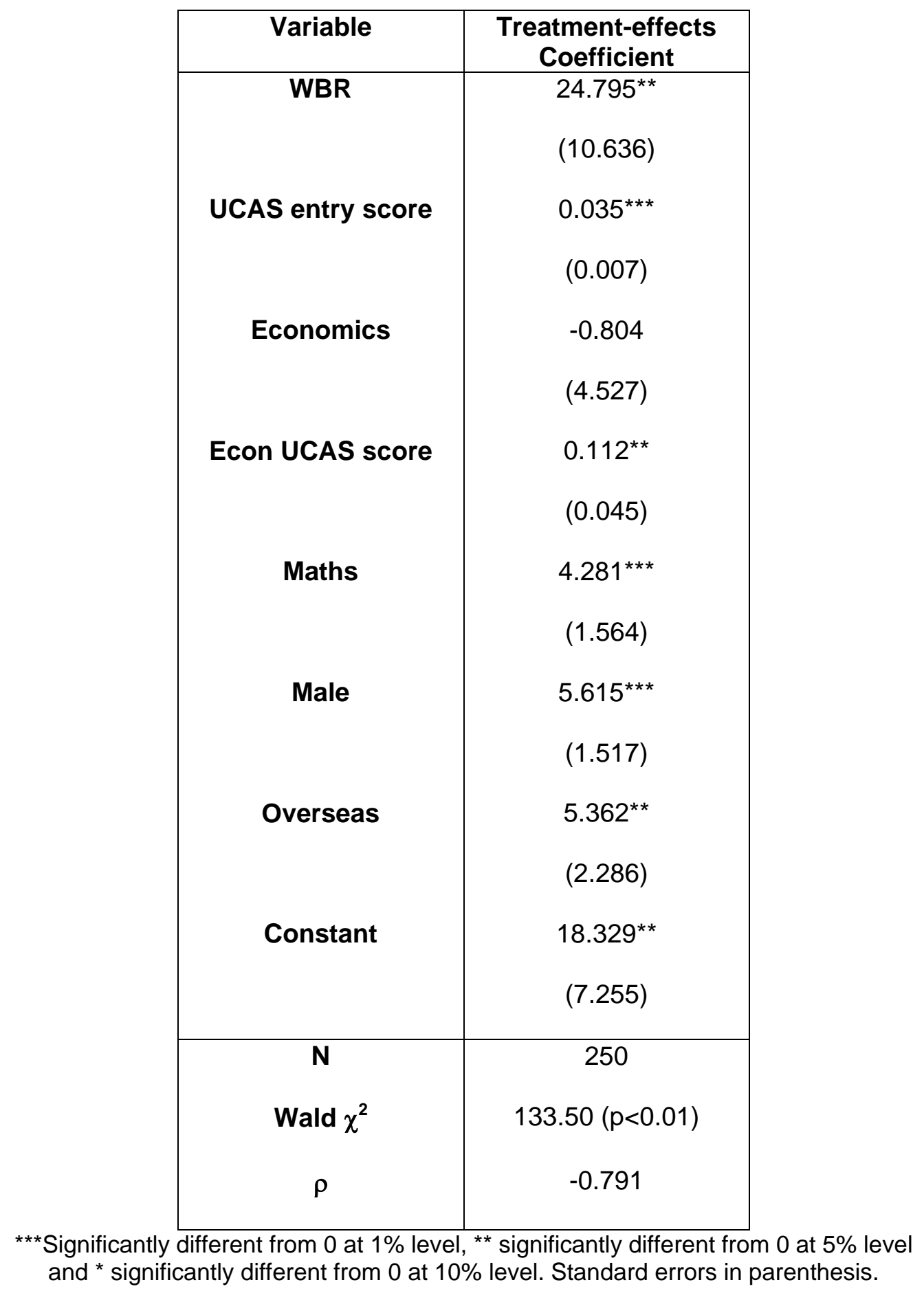


Table 8: Probit regression - the probability a student pays to access the WBR (Full sample)

\begin{tabular}{|c|c|}
\hline Variable & Marginal effect \\
\hline Age & -0.128 \\
Overseas & $(0.013)$ \\
Comprehensive & $-0.192^{\star \star \star}$ \\
& $(0.053)$ \\
Grammar & $0.142^{\star *}$ \\
& $(0.064)$ \\
\hline N & $0.191^{*}$ \\
Log-L & $(0.114)$ \\
LR test $\chi^{2}$ & 446 \\
Pseudo R & -292.123 \\
\hline
\end{tabular}

***Significantly different from 0 at $1 \%$ level, ** significantly different from 0 at $5 \%$ level and * significantly different from 0 at $10 \%$ level. Standard errors in parenthesis. 
Table 9: Treatment-effects regression explaining overall exam performance (Full sample)

\begin{tabular}{|c|c|}
\hline Variable & $\begin{array}{c}\text { Treatment-effects } \\
\text { Coefficient }\end{array}$ \\
\hline WBR & $49.479^{\star \star \star}$ \\
Male & $(17.389)$ \\
Overseas & $(1.534)$ \\
& $9.1619^{\star}$ \\
Constant & $(5.002)$ \\
& $24.268^{\star \star}$ \\
$\mathbf{N}$ & $(9.859)$ \\
\hline Wald $\chi^{2}$ & 446 \\
$\rho$ & $24.82(p<0.01)$ \\
\hline
\end{tabular}

***Significantly different from 0 at $1 \%$ level, ** significantly different from 0 at $5 \%$ level and * significantly different from 0 at $10 \%$ level. Standard errors in parenthesis. 